\title{
Do the Defects Make it Work? Defect Engineering in Pi-Conjugated Polymers and Their Solar Cells
}

Conference Paper NREL/CP-270-42565

May 2008

\section{Preprint}

D. Wang, M. Reese, N. Kopidakis, and B.A. Gregg National Renewable Energy Laboratory

Presented at the 33rd IEEE Photovoltaic Specialists Conference San Diego, California May 11-16, 2008 


\section{NOTICE}

The submitted manuscript has been offered by an employee of the Midwest Research Institute (MRI), a contractor of the US Government under Contract No. DE-AC36-99G010337. Accordingly, the US Government and MRI retain a nonexclusive royalty-free license to publish or reproduce the published form of this contribution, or allow others to do so, for US Government purposes.

This report was prepared as an account of work sponsored by an agency of the United States government. Neither the United States government nor any agency thereof, nor any of their employees, makes any warranty, express or implied, or assumes any legal liability or responsibility for the accuracy, completeness, or usefulness of any information, apparatus, product, or process disclosed, or represents that its use would not infringe privately owned rights. Reference herein to any specific commercial product, process, or service by trade name, trademark, manufacturer, or otherwise does not necessarily constitute or imply its endorsement, recommendation, or favoring by the United States government or any agency thereof. The views and opinions of authors expressed herein do not necessarily state or reflect those of the United States government or any agency thereof.

Available electronically at http://www.osti.gov/bridge

Available for a processing fee to U.S. Department of Energy and its contractors, in paper, from:

U.S. Department of Energy

Office of Scientific and Technical Information

P.O. Box 62

Oak Ridge, TN 37831-0062

phone: 865.576 .8401

fax: 865.576 .5728

email: mailto:reports@adonis.osti.gov

Available for sale to the public, in paper, from:

U.S. Department of Commerce

National Technical Information Service

5285 Port Royal Road

Springfield, VA 22161

phone: 800.553 .6847

fax: 703.605.6900

email: orders@ntis.fedworld.gov

online ordering: http://www.ntis.gov/ordering.htm 


\title{
DO THE DEFECTS MAKE IT WORK? DEFECT ENGINEERING IN PI-CONJUGATED POLYMERS AND THEIR SOLAR CELLS
}

\author{
Dong Wang, Matthew Reese, Nikos Kopidakis and Brian A. Gregg* \\ National Renewable Energy Laboratory, 1617 Cole Boulevard, Golden, Colorado 80401
}

\begin{abstract}
The charged defect density in common $\pi-$ conjugated polymers such as poly(3-hexylthiophene), $\mathrm{P} 3 \mathrm{HT}$, is around $10^{18} \mathrm{~cm}^{-3}$. Despite, or perhaps because of, this huge defect density, bulk heterojunction solar cells made from these polymers and a C60 derviative such as PCBM exhibit some of the highest efficiencies ( $5 \%)$ yet obtained in solid state organic photovoltaic cells. We discuss defects in molecular organic semiconductors and in $\pi$-conjugated polymers. These defects can be grouped in two categories, covalent and noncovalent. Somewhat analogous to treating amorphous silicon with hydrogen, we introduce chemical methods to modify the density and charge of the covalent defects in P3HT by treating it with electrophiles such as dimethyl sulfate and nucleophiles such as sodium methoxide. The effects of these treatments on the electrical and photovoltaic properties and stability of organic PV cells is discussed in terms of the change in the number and chemical properties of the defects. Finally, we address the question of whether the efficiency of OPV cells requires the presence of these defects which function as adventitious p-type dopants. Their presence relieves the resistance limitations usually encountered in cleaner organic semiconductors and can create built-in electric fields at junctions. These considerations lead toward the design of a new generation of OPV materials that replaces the covalent defects with purposely added dopants.
\end{abstract}

\section{INTRODUCTION}

Electronically, organic (i.e., excitonic) semiconductors, XSCs, are distinguished from most inorganic semiconductors by their low dielectric constants and localized carrier wavefunctions. These result in the predominance of electrostatic interactions in their photoelectrical properties. Thus excitons are formed upon light absorption rather than free electron hole pairs; the doping efficiency is often less than $1 \%$ because most added charges remain Coulombically bound to their countercharges;[1] and carrier mobilities show PooleFrenkel-like behavior.[2] In such low dielectric media it may be expected that charged defects, if present in significant concentration, would play a decisive role in the observed electrical behavior. Yet the role of charged defects in XSCs has been practically ignored.

Ironically, it seems that the most defect-laden materials have so far produced the highest efficiency organic PV cells, while highly purified molecular semiconductors show very poor results. One is tempted to ask: do the defects make it work? And if so, what can we learn from this counterintuitive result to make improved OPV cells? We first describe measurements of the defect density in one of the most commonly employed $\pi$-conjugated polymers, regioregular poly(3hexylthiophene), $\mathrm{P} 3 \mathrm{HT}$, and briefly discuss the two classes of defects in XSCs. Then chemical treatments of P3HT are introduced that modify the defects, and the resulting changes in photoelectrical properties of the polymer and OPV cells made from it are described. Finally some recent results about defects in molecular semiconductors and their effects on OPV efficiency are described.

\section{RESULTS AND DISCUSSION}

\section{Defect density}

Zero field conductivity measurements on spincast films of P3HT, coupled with time-of-flight hole mobility measurements provide an estimate of the free hole density, $p_{\mathrm{f}} \approx 10^{16}-10^{17} \mathrm{~cm}^{-3}$, with the lower range approachable only in extensively purified material.[3] The density of bound charges, however, should be far higher than $p_{f}$ given the low dielectric constant and excitonic nature of the polymer. Total charge densities around $p_{\mathrm{d}}$ $\sim 10^{18}-10^{19} \mathrm{~cm}^{-3}$ are thus expected in P3HT and other $\pi-$ conjugated polymers; this is some 14 orders of magnitude beyond the intrinsic level for a semiconductor of bandgap $\approx 2 \mathrm{eV}$. Charge densities in molecular semiconductors are several orders of magnitude lower than in $\pi-$ conjugated polymers, though still far beyond the intrinsic level. There is as yet little understanding of the chemical nature or physical influence of these charged defects.

Defects in organic semiconductors can be classified as either covalent or noncovalent.[2, 3] Noncovalent defects perturb only weak van der Waals or London forces between molecules. For example, imperfections in the crystal packing of closed shell (molecular) organic semiconductors create noncovalent defects. Since they involve only weak forces, they tend to produce shallow defects that are mainly uncharged. Covalent defects, on the other hand, perturb high energy covalent bonds, similar to dislocations in silicon, and have a greater probablility of creating charged states in the gap. Ideally the backbone in $\pi$-conjugated polymers (which consists of $s p^{2}$-hybridized carbons) would form a 


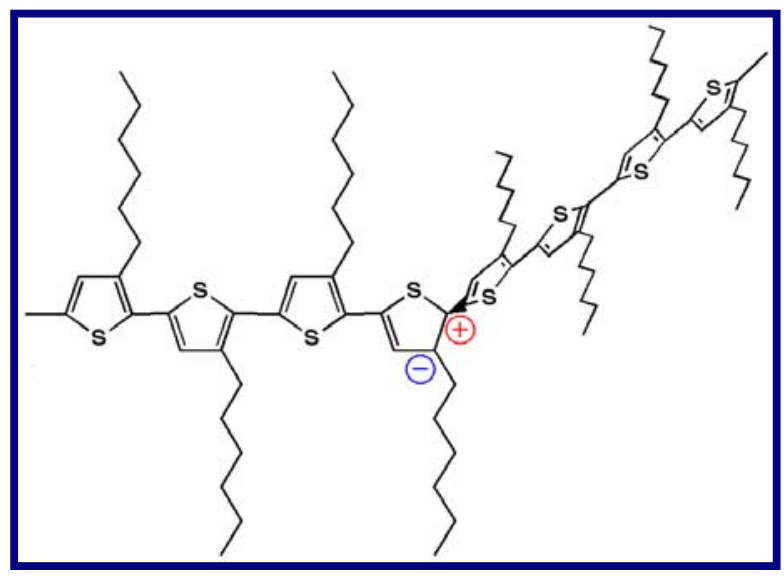

Figure 1. Illustration of a possible covalent defect in $\mathrm{P} 3 \mathrm{HT}$

planar conducting wire. But in solid films the backbone inevitably has a number of kinks and bends in it that perturb the planarity of the $s p^{2}$ carbons, thus deforming high energy $\pi$-bonds. Figure 1 shows a possible covalent defect in P3HT. We do not consider chemical impurities here, although they probably also play a role, and focus instead on morphological defects in the polymers since they appear to be the only source large enough to account for the equilibrium charge density.

\section{Chemical treatments}

From the viewpoint of organic chemistry, gap states in these polymers must be either easier to oxidize or reduce than band states and likewise should exhibit enhanced reactivity with either electrophiles or nucleophiles, respectively. Somewhat analogous to treating amorphous silicon with hydrogen to passivate gap states, we introduce methods of treating m-conjugated polymers with dimethyl sulfate, a methyl cation donor $\left(\mathrm{Me}_{2} \mathrm{SO}_{4}\right.$, an electrophile) and methoxide anion ( $\mathrm{MeO}^{-}$, a nucleophile). The details of the chemical reaction procedures and the characterization of the products will be reported elsewhere.[4] Here we briefly describe some of the results of the chemical treatments on $\mathrm{P} 3 \mathrm{HT}$ and OPV devices made from it. All P3HT films were annealled at $120^{\circ} \mathrm{C}$ for $30 \mathrm{~min}$. in a glove box before measuring

Table 1 summarizes some of the data. Methoxide anion is expected to react at positively charged (cationic or trapped hole) sites in the polymer and thus may decrease the free hole density. The zero field conductivity, $\sigma_{0}$, of methoxide-treated $\mathrm{P} 3 \mathrm{HT}$ decreases by about a factor of five compared to the untreated material while the hole mobility, $\mu_{p}$, increases slightly (Table 1 ). This results in a decrease in the calculated $p_{f}$ by approximately seven fold. Conversely, methyl cation is expected to react at the anionic sites and may substitute the electro-inactive sulfate ion for bound electrons. This reaction is thus equivalent to a p-type doping process, albeit, with a counterion (sulfate) that is slightly mobile in the film. In this case, $\sigma_{0}$ increases $\sim 3$ fold caused by a corresponding increase in $\mu_{\mathrm{p}}$, while $p_{\mathrm{f}}$ remains almost constant.

The zero field activation energy of the current, $E_{\mathrm{aJ} 0}$, increases slightly upon treatment with $\mathrm{MeO}^{-}$(Table 1) consistent with the removal of some of the shallower traps. On the other hand, $E_{\mathrm{aJo}}$ decreases upon treatment with $\mathrm{Me}_{2} \mathrm{SO}_{4}$. This may be an electrostatic effect as substituting a sulfate ion not bound to the polymer chain for an electron on the chain may result in shallower potential wells for the holes.

Table 1.

\begin{tabular}{|c|c|c|c|c|c|}
\hline Treatment & $\begin{array}{l}\sigma_{0}, \mathrm{X} \\
10^{-7} \\
\mathrm{~S} / \mathrm{cm}\end{array}$ & $\begin{array}{l}E_{\mathrm{aJ} 0}, \\
\mathrm{meV}\end{array}$ & $\begin{array}{c}L_{\mathrm{ex}}, \\
\mathrm{nm}\end{array}$ & $\begin{array}{c}\mu_{\mathrm{p}}, \mathrm{x} 10^{-4} \\
\mathrm{~cm}^{2} / \mathrm{Vs}\end{array}$ & $\begin{array}{c}p_{\mathrm{f}}, \underset{\mathrm{x}}{\mathrm{cm}} \mathrm{cm}^{-3} \\
\mathrm{~cm}^{16}\end{array}$ \\
\hline none & 14 & 233 & 7 & 1.2 & 7.3 \\
\hline $\mathrm{MeO}^{-}$ & 3 & 276 & 9 & 1.8 & 1.0 \\
\hline $\mathrm{Me}_{2} \mathrm{SO}_{4}$ & 46 & 210 & 13 & 4.2 & 6.8 \\
\hline
\end{tabular}

\section{Exciton diffusion length}

When excitons, rather than free electrons and holes, are formed upon light absorption, the exciton diffusion length, $L_{e x}$, becomes a key parameter. Excitons must be able to reach an interface where they can dissociate into an electron in one phase and a hole in the other in order to contribute to the photocurrent. When $L_{e x}$ $<1 / \alpha$, where $\alpha$ is the absorption length, the only way to absorb most of the light within $L_{e x}$ of an interface is to nanostructure the interface.[2] This is the strategy employed in bulk heterojunction cells where $L_{\mathrm{ex}}<10 \mathrm{~nm}$ while $\alpha>100 \mathrm{~nm}^{-1}$. Since charged defects are expected to be efficient quenchers of excitons, it is perhaps not surprising that $L_{e x}$ in the m-conjugated polymers is so short. If the total charge density in P3HT is $\sim 10^{18} \mathrm{~cm}^{-3}$, the average distance between charges is only $\sim 10 \mathrm{~nm}$.

Treatment of $\mathrm{P} 3 \mathrm{HT}$ with methoxide anion increases $L_{e x}$ slightly, however treatment with methyl cation increases $L_{e x}$ by a factor of $\sim 2$. This suggests that bound electrons are more efficient quenchers of excitons than bound holes. The changes in $\mu_{\mathrm{p}}$ for the two treatments (Table 1) also suggest that bound electrons diminish the hole mobility far more than bound holes. This seems reasonable since a free hole will be repelled from a bound hole and thus tend to go around it, while it would be attracted to a bound electron and tend to be trapped by it or recombine.

\section{Bulk heterojunction OPV cells}

A number of OPV devices were made with the $\mathrm{Me}_{2} \mathrm{SO}_{4}$-treated and untreated P3HT blended with PCBM. The bulk heterojunction cells were of a standard configuration: ITO/Pedot-PSS/P3HT-PCBM/AI. On average, there was little difference between treated and untreated P3HT cells. This may be because the bulk heterojunction cells are already optimized for untreated P3HT and are not limited by either of the parameters improved by the treatment, $L_{e x}$ and $\mu_{p}$ (the cells are limited primarily by $V_{\text {oc }}$ ). There was, however, in some samples a dramatic improvement in the stability of the 
devices in air with the treated polymer. Figure 2 shows that when processed in air rather than in the glovebox, the untreated polymer cell is strongly degraded while the treated material actually improves slightly compared to the glovebox-prepared cell. This is an important result since the stability of organic semiconductors and OPV cells is a major concern.

\section{Defects in molecular semiconductors}

Our chemical treatments of $\mathrm{P} 3 \mathrm{HT}$ resulted in only small changes in charge density in the films, less than an order of magnitude, and this was not sufficient to result in major changes in OPV cell performance. A recent paper from the Peumans group, however, reported major changes in OPV cell efficiency upon rigorous purification of a molecular semiconductor, perylene bisphenethylimide, PPEI.[4] In a bilayer heterojunction cell with copper phthalocyanine as the "p-type" material, the efficiency decreased 170 fold after rigorous purification of the PPEI. The authors ascribe this to a loss of adventitious n-type dopants upon purification which led to a sharp decrease in electric field across the heterojunction. The interfacial field was necessary to avoid geminate recombination of the Coulombically bound electron hole pair created by exciton dissociation at the interface. Thus it was the adventitous defects that allowed the impure material to function efficiently. It is worth noting that similar interfacial recombination in a P3HT/PCBM bulk heterojunction is apparently prevented only by the large amount of thermal energy $(\sim 0.9 \mathrm{eV})$ released when excitons dissociate in this system. This loss of energy is primarily responsible for the low $V_{\text {oc }}$ in these cells. Unfortunately, a number of similar polymers that lose only $0.6-0.8 \mathrm{eV}$ upon exciton dissociation show a greatly diminished yield of separated carriers.[5] Apparently, losing at least $\sim 0.9 \mathrm{eV}$ of energy is required to obtain efficient charge separation in the current generation of bulk heterojunction cells.

\section{CONCLUSIONS AND FUTURE DIRECTIONS}

Researchers are just beginning to realize the extent to which the properties of exctionic semiconductors are governed by defects. Most theoretical models continue to ignore the presence of trapped and mobile charges in these materials. We measured the concentration of free holes in P3HT $\left(p_{\mathrm{f}} \approx 7 \times 10^{16} \mathrm{~cm}^{-3}\right)$ and employed that to estimate the total charge density $\left(10^{18}-10^{19} \mathrm{~cm}^{-3}\right)$. Of course, there must be approximately equal quantities of positive and negative charges, and many of them will be somewhat mobile, unlike true dopants. We introduced chemical methods to treat $\mathrm{P} 3 \mathrm{HT}$ that improved the exciton diffusion length, carrier mobility and polymer stability.

The presence of a large quantitiy of adventitious dopants in the form of charged defects greatly increases the conductivity of XSCs and also can create an electric field at a heterojunction sufficient to separate photogenerated charge carriers. However, since the "dopants" are not necessarily bound to the lattice, such junction fields may disappear over time.[1] Currently, the

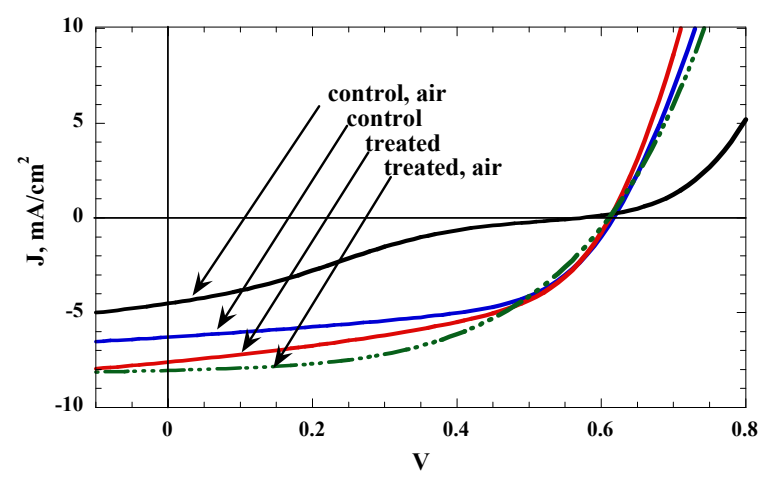

Figure 2. $J-V$ curves of four bulk heterojunction OPV cells under 1 sun illumination: two controls with untreated $\mathrm{P} 3 \mathrm{HT}$ and two with $\mathrm{Me}_{2} \mathrm{SO}_{4}$-treated $\mathrm{P} 3 \mathrm{HT}$. One of each was prepared entirely in the glovebox while the other two were prepared in air.

most efficient OPV cells are based on highly defective materials, probably because only these are "doped" highly enough to function well. It appears that, yes, the defects do make them work. But these same defects quench excitons, decrease carrier mobility, make the materials unstable toward photo-oxidation, etc. A new approach seems necessary before the true potential of OPV can be realized. Employing highly pure XSCs doped with purposely added and immobile dopants seems like a superior method of creating efficient and stable OPV cells. The synthesis and characterization of the first generation of such materials is in progress.

\section{ACKNOWLEDGEMENTS}

This work was supported by the U.S. Department of Energy under Contract No. DE-AC3699G010337

\section{REFERENCES}

[1] B. A. Gregg, R. A. Cormier, "Doping Molecular Semiconductors: n-Type Doping of a Liquid Crystal Perylene Diimide", J. Am. Chem. Soc. 2001, 123, 7959.

[2] B. A. Gregg, "Excitonic Solar Cells", J. Phys. Chem. B 2003, 107, 4688. B. A. Gregg, "Toward a Unified Treatment of Electronic Processes in Organic Semiconductors", J. Phys. Chem. B, 2004, 108, 17285.

[3] D. Wang, N. Kopidakis, X. Ai, B. A. Gregg, "Electronic Defects in $\pi$-Conjugated Polymer Films and Their Chemical Modification" submitted to J. Phys. Chem. B 2008.

[4] A. Liu, et al., "Control of Electric Field Stregth and Orientation at the Donor-Acceptor Interface in Organic Solar Cells", Adv. Mater., 2008, 20, 1065.

[5] H. Ohkita, et al., "Charge carrier formation in polythiophene/fullerene blend films studied by transient absorption spectroscopy" J. Am. Chem. Soc. 2008, 130, 3030. 


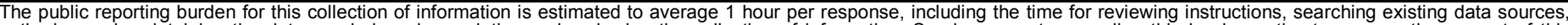

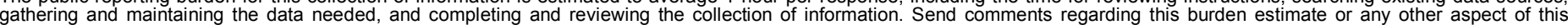

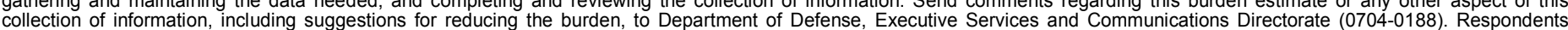

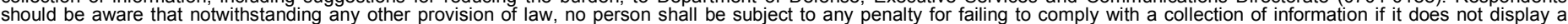

should be aware that notwithstandin.

PLEASE DO NOT RETURN YOUR FORM TO THE ABOVE ORGANIZATION.

\section{REPORT DATE (DD-MM-YYYY) May 2008 \\ 2. REPORT TYPE Conference Paper}

4. TITLE AND SUBTITLE

Do the Defects Make it Work? Defect Engineering in Pi-Conjugated

Polymers and Their Solar Cells: Preprint

6. AUTHOR(S)

D. Wang, M. Reese, N. Kopidakis, and B.A. Gregg
3. DATES COVERED (From - To)

11-16 May 2008

5a. CONTRACT NUMBER

DE-AC36-99-GO10337

5b. GRANT NUMBER

5c. PROGRAM ELEMENT NUMBER

5d. PROJECT NUMBER

NREL/CP-270-42565

5e. TASK NUMBER

PVA72801

5f. WORK UNIT NUMBER

7. PERFORMING ORGANIZATION NAME(S) AND ADDRESS(ES)

National Renewable Energy Laboratory

1617 Cole Blvd.

Golden, CO 80401-3393

9. SPONSORING/MONITORING AGENCY NAME(S) AND ADDRESS(ES)
8. PERFORMING ORGANIZATION

REPORT NUMBER

NREL/CP-520-42565

10. SPONSOR/MONITOR'S ACRONYM(S) NREL

11. SPONSORING/MONITORING AGENCY REPORT NUMBER

\section{DISTRIBUTION AVAILABILITY STATEMENT}

National Technical Information Service

U.S. Department of Commerce

5285 Port Royal Road

Springfield, VA 22161

\section{SUPPLEMENTARY NOTES}

The charged defect density in common $\pi$-conjugated polymers such as poly(3-hexylthiophene), $\mathrm{P} 3 \mathrm{HT}$, is around $10^{18} \mathrm{~cm}^{-3}$. Despite, or perhaps because of, this huge defect density, bulk heterojunction solar cells made from these polymers and a C60 derivative such as PCBM exhibit some of the highest efficiencies ( $5 \%)$ yet obtained in solid state organic photovoltaic cells. We discuss defects in molecular organic semiconductors and in $\pi$-conjugated polymers. These defects can be grouped in two categories, covalent and noncovalent. Somewhat analogous to treating amorphous silicon with hydrogen, we introduce chemic methods to modify the density and charge of the covalent defects in $\mathrm{P} 3 \mathrm{HT}$ by treating it with electrophiles such as dimethyl sulfate and nucleophiles such as sodium methoxide. The effects of these treatments on the electrical and photovoltaic propertie and stability of organic PV cells is discussed in terms of the change in the number and chemical properties of the defects. Finally, we address the question of whether the efficiency of OPV cells requires the presence of these defects which function as adventitious p-type dopants. Their presence relieves the resistance limitations usually encountered in cleaner organic semiconductors and can create built-in electric fields at junctions.

\section{SUBJECT TERMS}

PV; OPV; excitonic semiconductors; p-type dopants; electrophiles; defect densities;

\begin{tabular}{|c|c|c|}
\hline $\begin{array}{l}\text { a. REPORT } \\
\text { Unclassified }\end{array}$ & $\begin{array}{l}\text { b. ABSTRACT } \\
\text { Unclassified }\end{array}$ & $\begin{array}{l}\text { c. THIS PAGE } \\
\text { Unclassified }\end{array}$ \\
\hline
\end{tabular}

\begin{tabular}{l|l|}
\hline 17. LIMITATION & 18. NUMBER \\
OF ABSTRACT & OF PAGES \\
UL &
\end{tabular}

19a. NAME OF RESPONSIBLE PERSON

19b. TELEPHONE NUMBER (Include area code) 